\title{
Differential vulnerability of substantia nigra and corpus striatum to oxidative insult induced by reduced dietary levels of essential fatty acids
}

\author{
Henriqueta D. Cardoso ${ }^{1}$, Priscila P. Passos ${ }^{1}$, Claudia J. Lagranha ${ }^{2}$, Anete C. Ferraz ${ }^{3}$, \\ Eraldo F. Santos Júnior ${ }^{1}$, Rafael S. Oliveira ${ }^{1}$, Pablo E. L. Oliveira ${ }^{1}$, Rita de C. F. Santos ${ }^{1}$, \\ David F. Santana ${ }^{1}$, Juliana M. C. Borba ${ }^{4}$, Ana P. Rocha-de-Melo ${ }^{4}$, Rubem C. A. Guedes ${ }^{4}$, \\ Daniela M. A. F. Navarro ${ }^{5}$, Geanne K. N. Santos ${ }^{5}$, Roseane Borner 6 , Cristovam W. Picanço-Diniz ${ }^{6}$, \\ Eduardo I. Beltrão ${ }^{7}$, Janilson F. Silva ${ }^{7}$, Marcelo C. A. Rodrigues ${ }^{1}$ and Belmira L. S. Andrade da Costa ${ }^{1 *}$

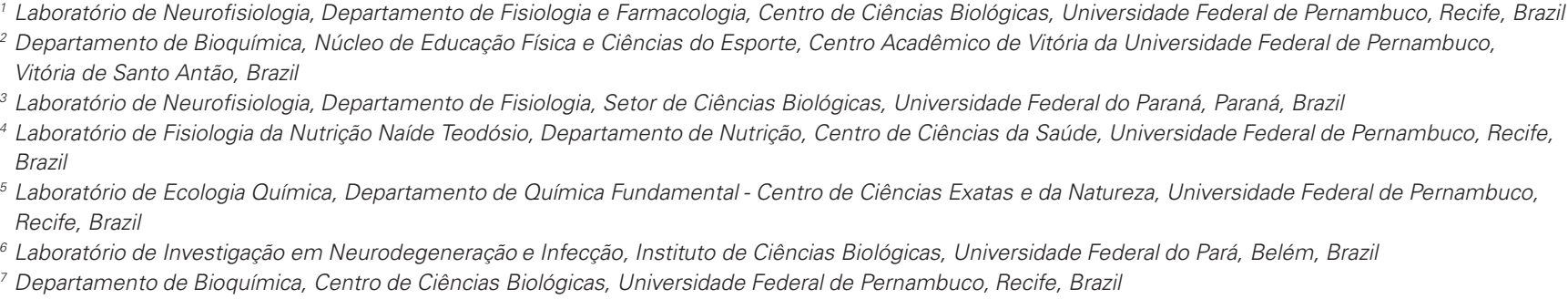

Edited by:

João R. M. Oliveira, Federal

University of Pernambuco, Brazil

Reviewed by:

João R. M. Oliveira, Federal

University of Pernambuco, Brazil

Gina Rinetti, University of California,

San Francisco, USA

\section{*Correspondence:}

Belmira L. S. Andrade da Costa,

Departamento de Fisiologia e

Farmacologia, Centro de Ciências

Biológicas, Universidade Federal de

Pernambuco, Av. Prof. Moraes Rego

1235, Cidade Universitária, Recife,

Pernambuco, CEP 50670-901, Brazil.

e-mail: bl@ufpe.br;

belmira@gmail.com
Oxidative stress (OS) has been implicated in the etiology of certain neurodegenerative disorders. Some of these disorders have been associated with unbalanced levels of essential fatty acids (EFA). The response of certain brain regions to OS, however, is not uniform and a selective vulnerability or resilience can occur. In our previous study on rat brains, we observed that a two-generation EFA dietary restriction reduced the number and size of dopaminergic neurons in the substantia nigra (SN) rostro-dorso-medial. To understand whether OS contributes to this effect, we assessed the status of lipid peroxidation (LP) and anti-oxidant markers in both SN and corpus striatum (CS) of rats submitted to this dietary treatment for one (F1) or two (F2) generations. Wistar rats were raised from conception on control or experimental diets containing adequate or reduced levels of linoleic and $\alpha$-linolenic fatty acids, respectively. LP was measured using the thiobarbituric acid reaction method (TBARS) and the total superoxide dismutase (t-SOD) and catalase (CAT) enzymatic activities were assessed. The experimental diet significantly reduced the docosahexaenoic acid (DHA) levels of $S N$ phospholipids in the F1 ( 28\%) and F2 ( 50\%) groups. In F1 adult animals of the experimental group there was no LP in both SN and CS. Consistently, there was a significant increase in the t-SOD activity $(p<0.01)$ in both regions. In EF2 young animals, degeneration in dopaminergic and non-dopaminergic neurons and a significant increase in LP $(p<0.01)$ and decrease in the CAT activity $(p<0.001)$ were detected in the SN, while no inter-group difference was found for these parameters in the CS. Conversely, a significant increase in t-SOD activity $(p<0.05)$ was detected in the CS of the experimental group compared to the control. The results show that unbalanced EFA dietary levels reduce the redox balance in the SN and reveal mechanisms of resilience in the CS under this stressful condition.

Keywords: substantia nigra, corpus striatum, oxidative stress, superoxide dismutase, catalase, lipid peroxidation, DHA, neurodegeneration

\section{INTRODUCTION}

Docosahexaenoic acid (DHA) and arachidonic acid (AA) are long chain polyunsaturated fatty acids (LC-PUFA) which play important roles as critical modulators of brain function under physiological or pathological conditions (Zhang et al., 2011). They are derived from the essential fatty acids (EFA) $\alpha$-linolenic and linoleic acids, respectively, and can exert opposite effects on brain metabolism (Schmitz and Ecker, 2008). Imbalance in their levels, early in life, and especially DHA deficiency, can decrease anti-inflammatory responses that can induce neurodegeneration (Yavin, 2006; Schmitz and Ecker, 2008). Recent studies using microarray technology have shown that DHA is able to regulate the transcription of many genes related to oxidative stress (OS), cell signaling, and apoptosis (Kitajka et al., 2004; Lapillonne et al., 
2004; Yavin, 2006). Consistent with this evidence, it has been demonstrated that DHA protects against peroxidative damage of lipids and proteins in developing and adult brains in experimental models of ischemia-reperfusion (Glozman et al., 1998; Green et al., 2001; Pan et al., 2009; Mayurasakorn et al., 2011) or reduce OS-induced apoptosis of retina photoreceptors (Rotstein et al., 2003). Moreover, the DHA-derived docosanoid, named neuroprotectin D1, protects human retinal pigment epithelial cells from OS (Mukherjee et al., 2004) as well as inhibits brain ischemia-reperfusion-mediated leukocyte infiltration and proinflammatory gene expression (Marcheselli et al., 2003).

It is well established that OS is caused by the disequilibrium between the production and detoxification of highly reactive oxygen species (ROS), including singlet oxygen, superoxide anion, and hydrogen peroxide, which can disrupt the redox balance inside cells if not properly neutralized. The superoxide anion is known to induce protein and nucleic acid dysfunction and to initiate lipid peroxidation (LP) (Kohen and Nyska, 2002). Endogenous anti-oxidant mechanisms against superoxides include a series of linked enzyme reactions. The first of these enzymes is superoxide dismutase (SOD; EC1.15.1.1), that converts superoxide anion to hydrogen peroxide $\left(\mathrm{H}_{2} \mathrm{O}_{2}\right)$, which can be removed by catalase (CAT; EC 1.11.1.6) and/or glutathione peroxidase (GPx; EC 1.11.1.9) (Kohen and Nyska, 2002; Melo et al., 2011).

Neuron response to OS is not uniform in the brain. This differential vulnerability depends on a number of factors including high intrinsic OS, high demand for ROS-based intracellular signaling, low ATP production, mitochondrial dysfunction, and high inflammatory response (Wang and Michaelis, 2010). Strong evidence indicates that OS may be one of the most important mechanisms involved in the etiology and evolution of a number of neurodegenerative diseases (Hashimoto and Hossain, 2011; Thomas and Beal, 2007; Melo et al., 2011). DHA is considered as a potential target for therapeutic intervention in some of these disorders, including Parkinson's Disease (PD), where the dopaminergic neurons of substantia nigra $(\mathrm{SN})$ are especially affected by OS and mitochondrial dysfunction (Jenner et al., 1992; Sayre et al., 2001). In experimental models of PD, for example, it has been shown that the dietary supplementation of DHA may partially restore dopaminergic neurotransmission after 6-hydroxidopamine (6-OHDA)- or 1-methyl-4-phenyl-1,2,3,6tetrahydropyridine (MPTP)-induced striatal lesions which produce OS (Bousquet et al., 2008; Cansev et al., 2008). Moreover, DHA supplementation is able to increase the SOD activity in the corpus striatum (CS) (Sarsilmaz et al., 2003) as well as significantly decrease cyclooxigenase-2 activity and prostaglandin E2 levels in the SN, decreasing MPTP-induced dopaminergic cell death (Ozsoy et al., 2011). Conversely, combination of successive parity and $\alpha$-linolenic acid deficient maternal diet reduced the number of dopaminergic neurons in the rat SN pars compacta and ventral tegmental area of adult offspring (Ahmad et al., 2008).

Recent evidence from our laboratory, adopting a two generation model of EFA dietary restriction and stereological assessment, showed a differential vulnerability of two distinct SN dopaminergic cell populations to this type of nutritional insult. In addition to a reduction in the number of dopaminergic neurons in the SN rostro-dorso-medial region, this dietary treatment was able to change body and brain weights, TH protein levels, and the size of these neurons in young animals (Passos et al., 2012). The mechanisms involved in such effects are not yet completely understood. It is well established that under physiological conditions, the SN has unique biochemical features which provide a higher vulnerability to OS (Kidd, 2000) when compared to other brain regions, including the CS (Mythri et al., 2011). The present study was conducted to test the hypothesis that OS can be a potential mechanism involved in the neurodegeneration of SN dopaminergic cells induced by EFA dietary restriction. We tested whether this restriction for one or two generations could induce LP or modify the anti-oxidant activity of SOD or CAT in the SN and CS of rats.

\section{MATERIALS AND METHODS}

All procedures were approved by the Ethics Committee for Animal Research of Federal University of Pernambuco (protocol \# 009428/200633), which complies with the "Principles of Laboratory Animal Care” (NIH, Bethesda, USA). Adult female Wistar rats weighing 200-250 g were fed from mating throughout pregnancy and lactation on a control or experimental diets, each containing approximately $400 \mathrm{Kcal} 100 \mathrm{~g}$ and differing only in the lipid source. The diets were prepared according to Soares et al. (1995) and meet all current nutrient standards for rat pregnancy and growth (Table 1). The control diet contained $50 \mathrm{~g} / \mathrm{Kg}$ of soybean oil with adequate amounts of saturated, monounsaturated, $\alpha$-linolenic (6\% of total fatty acids) and linoleic (56\% of total fatty acids) acids. The experimental diet contained $50 \mathrm{~g} / \mathrm{Kg}$ of coconut oil (from Babaçu, Orbignia martiana) with reduced levels of linoleic and $\alpha$-linolenic acids and higher levels of saturated (2-fold) and monounsaturated (2.5-fold) fatty acids (Table 2).

Table 1 | Diet composition (grams/100g diet).

\begin{tabular}{lcc}
\hline Ingredients & Control diet & Experimental diet \\
\hline Casein & 20.7 & 20.7 \\
Cellulose & 1.8 & 1.8 \\
Corn starch & 46.8 & 46.8 \\
Sucrose & 21.0 & 21.0 \\
Soyabean oil & 5.0 & - \\
Coconut oil & - & 5.0 \\
Vitamin mix & 0.9 & 0.9 \\
Mineral mix & 3.7 & 3.7 \\
D.L-Cystine & 0.1 & 0.1 \\
Butyl hydroxytoluene & 0.001 & 0.001 \\
\hline Kcal/100 g & 399.1 & 400.5
\end{tabular}

a Vitamin mixture (Rhoster Ind.Com. LTDA. SP. Brazil) containing (m\%): folic acid (20); niacin (300); biotin (2); calcium pantothenate 160; pyridoxine (70); riboflavin (60); thiamine chloride (60); vitamin B12 (0.25); vitamin K1 (7.5). Additionally containing (Ul\%): vitamin A 40.000; vitamin D3 10.000; vitamin E (750).

${ }^{b}$ Mineral mixture (Rhoster Ind. Com. LTDA. SP. Brazil) containing (m\%): CaHP04 (38); K2HPO4 (24); CaCO3 (18.1); NaF (0.1); NaCl(7.0); MgO (2.0); MgSO4 7H2O (9.0); FeSO4 7H2O (0.7); ZnSO4 H2O (0.5); $\mathrm{MnSO}+\mathrm{H} 20$ (0.5); CuSO4 $5 \mathrm{H} 20$ (0.1); Al2 (SO4)3K2SO4 24H2O (0.02); Na2SeO3 5H2O (0.001); $\mathrm{KCl}(0.008)$. 
Table 2 | Fatty acid composition of the diets ( $\%$ of total fatty acids).

\begin{tabular}{|c|c|c|}
\hline Fatty acids & Control diet & Experimental diet \\
\hline 8 & 0.02 & 3.27 \\
\hline 10 & 0.03 & 3.95 \\
\hline 11 & nd & 0.07 \\
\hline 12 & 0.20 & 28.04 \\
\hline 13 & nd & 0.06 \\
\hline 14 & 0.19 & 19.56 \\
\hline 15 & 0.02 & 0.02 \\
\hline 16 & 9.27 & 11.32 \\
\hline 17 & nd & 0.02 \\
\hline 18 & 15.31 & 0.72 \\
\hline 20 & 0.33 & 0.16 \\
\hline 22 & 0.51 & 0.08 \\
\hline 23 & 0.07 & 0.02 \\
\hline 24 & 0.04 & nd \\
\hline Total saturated & 26.01 & 67.29 \\
\hline $16: 1$ & 2.72 & 0.06 \\
\hline 18:1n9 & 9.36 & 23.51 \\
\hline $20: 1$ & 0.24 & 0.16 \\
\hline Total monounsaturated & 12.32 & 23.73 \\
\hline $18: 2 \mathrm{n} 6$ & 55.36 & 8.10 \\
\hline $18: 3 n 3$ & 6.04 & 0.49 \\
\hline $20: 2$ & 0.04 & 0.06 \\
\hline $20: 5 n 3$ & 0.03 & nd \\
\hline $22: 2 n$ & 0.05 & 0.04 \\
\hline $22: 6 n 3$ & 0.13 & 0.06 \\
\hline Total polyunsaturated & 61.65 & 8.75 \\
\hline $18: 2 n 6 / 18: 3 n 3$ & 9.17 & 16.39 \\
\hline
\end{tabular}

nd, not detected. Bold values indicate $p<0.001$.

Rat offspring ( $n=112)$ were the object of the present study and only males were used for the experimental assays. Litters were culled to six pups on postnatal day 1 and weaned on postnatal day 21. Dams and pups were distributed into two main groups according to the nutritional condition: control (C) and experimental (E) rats. After weaning, pups were separated and fed ad libitum the same diet as their respective mothers. First generation (CF1 and EF1) male rats were weighed and evaluated for biochemical parameters related to LP and anti-oxidant markers at 90-110 days. The remaining males and females were allowed to mate to provide the second-generation groups (CF2 and EF2), which were analyzed at 30-42 days. In each group, animals were sampled randomly from different litters, housed three per cage in a room maintained at $22 \pm 2{ }^{\circ} \mathrm{C}$ with $67 \%$ relative air humidity and kept on a $12 \mathrm{~h} \mathrm{light/dark} \mathrm{cycle} \mathrm{(lights} \mathrm{on} \mathrm{6:00} \mathrm{h).}$

Each experimental day, six animals per group were anesthetized with isofluorane and then decapitated. The regions containing the $\mathrm{SN}$ or CS were rapidly dissected in $0.9 \%(\mathrm{w} / \mathrm{v}) \mathrm{NaCl}$ solution at $2{ }^{\circ} \mathrm{C}$. After weighing, the pooled tissue was homogenized in a $0.9 \%(\mathrm{w} / \mathrm{v}) \mathrm{NaCl}$ solution $(1: 10)$ at $4^{\circ} \mathrm{C}$ and centrifuged for $10 \mathrm{~min}$ at $1000 \mathrm{~g}$ at $4^{\circ} \mathrm{C}$ for an analysis of $\mathrm{LP}$ for the determination of thiobarbituric acid-reactive substances (TBARS) level and for $10 \mathrm{~min}$ at $10,000 \mathrm{~g}$ at $4^{\circ} \mathrm{C}$ in order to assess either the total $(\mathrm{Cu}-\mathrm{Zn}$ and $\mathrm{Mn})$ superoxide dismutase (t-SOD) and catalase enzymatic activities. An aliquot of supernatant was analyzed for total protein content using a bicinchroninic acid protein kit (Sigma-Aldrich, St. Louis, MO).

\section{LIPID PEROXIDATION}

LP was measured by estimating malondialdehyde (MDA) using a thiobarbituric acid (TBA) reaction (TBARS method) according to Ohkawa et al. (1979). In the TBA test reaction, MDA or MDAlike substances and TBA react to produce a pink pigment with maximum absorption at $532 \mathrm{~nm}$. The reaction was developed by the sequential addition of $0.2 \mathrm{~mL}$ of $8.1 \%$ sodium duodecil sulfate, $1.5 \mathrm{~mL}$ of $20 \%$ acetic acid ( $\mathrm{pH} 3.5$ ), and $1.5 \mathrm{~mL}$ of $0.8 \%$ TBA solutions in a boiling water-bath for $30 \mathrm{~min}$ to triplicates of supernatants. After tap water cooling, $1.5 \mathrm{~mL}$ of n-buthanol / pyridine $(15: 1 \mathrm{v} / \mathrm{v})$ was added to the sample, centrifuged at $2500 \mathrm{~g}$ for $10 \mathrm{~min}$ and the organic phase was read at $532 \mathrm{~nm}$ using a plate reader. The results were expressed as nmol per $\mathrm{mg}$ of protein using a standard curve generated using different concentrations 1,1,3,3-tetramethoxypropane solution. The control SN and CS samples were incubated in a $30 \mu \mathrm{M}$ sodium nitroprusside (SNP) solution for $45 \mathrm{~min}$ before the assay and used as positive controls for LP.

\section{SUPEROXIDE DISMUTASE (SOD) ASSAY}

Assessment of total SOD ( $\mathrm{t}$-SOD) enzymatic activity was performed according to Misra and Fridovich, (1972) at $25^{\circ} \mathrm{C}$. Triplicates of SN or CS supernatants $(100 \mu \mathrm{L})$ were previously incubated in a water bath at $37^{\circ} \mathrm{C}$ and then added to $880 \mu \mathrm{L}$ of $0.05 \%$ sodium carbonate solution $\mathrm{pH} 10.2$ in $0.1 \mathrm{mM}$ EDTA. The reaction was developed by adding $20 \mu \mathrm{L}$ of $30 \mathrm{mM}$ epinephrine (in $0.05 \%$ acetic acid). The absorbance was measured at $480 \mathrm{~nm}$ for $4 \mathrm{~min}$. One unit of t-SOD was defined as the enzyme amount causing 50\% inhibition of epinephrine oxidation. Tissue t-SOD enzymatic activity was also expressed as units per milligram of protein (U/mg protein). Positive controls were obtained incubating control homogenate samples of SN and CS in a $30 \mu \mathrm{M}$ SNP solution for $45 \mathrm{~min}$ before the enzymatic assay.

\section{CATALASE (CAT) ASSAY}

CAT activity was measured according to Aebi (1984). The rate constant $\mathrm{k}$ of $\mathrm{H}_{2} \mathrm{O}_{2}$ decomposition under our experimental conditions of temperature $\left(\sim 20^{\circ} \mathrm{C}\right)$ and $\mathrm{pH}(7.0)$ was determined to be $4.6 \times 10^{7}$ by measuring the absorbance changes per minute, for $4 \mathrm{~min}$. The enzymatic activity was expressed as the $\mathrm{H}_{2} \mathrm{O}_{2}$ consumed in $\mathrm{nM} / \mathrm{min} / \mathrm{mg}$ protein. Positive controls for catalase activity were obtained by incubation of SN and CS homogenates of the control group in increasing concentrations of $\mathrm{H}_{2} \mathrm{O}_{2}(3.156$ to $100 \mu \mathrm{M}$ ) for $30 \mathrm{~min}$ at $37^{\circ} \mathrm{C}$ before the enzymatic assay.

\section{STATISTICAL ANALYSIS OF OXIDATIVE STRESS PARAMETERS AND BODY WEIGHT}

All biochemical experiments were carried out in triplicate and repeated at least twice. Six animals from three litters per group were used each time. A total of 38 and 58 animals were used in the F1 and F2 generations, respectively. Biochemical data of TBARS levels, t-SOD, and catalase enzymatic activity were plotted using GraphPad Prism 5.0 software and the statistical analysis 
was performed using ANOVA followed by Tukey as the post-hoc test or Student's $t$-test in some cases. The analysis of body weight was carried out using unpaired Student's $t$-test. Differences were considered significant when $p<0.05$.

\section{FLUORO JADE C (FJC) ASSAY}

Considering our recent evidence that a loss of $\mathrm{SN}$ dopaminergic cells is induced by EFA dietary restriction for two generations (Passos et al., 2012), FJC, a polyanionic fluorescein derivative, was applied to examine signals of neurodegeneration. It has been shown that this protocol specifically labels damaged neurons and not glial cells in the SN and CS (Bian et al., 2007; Ehara and Ueda, 2009) when these regions are submitted to certain types of insult, especially under conditions that induce OS (Ehara and Ueda, 2009; Li et al., 2009; Yang et al., 2011).

Animals from the F1 and F2 groups ( $n=6$ /group) were anesthetized with a sodium pentobarbital solution $(100 \mathrm{mg} / \mathrm{kg}$, i.p. Sigma-Aldrich, St. Louis, MO), perfused with a $0.9 \% \mathrm{NaCl}$ solution, followed by $4 \%$ paraformaldehyde in a phosphate buffered saline (PBS), pH 7.4. The brains were post-fixed in the same fixative for two hours, rinsed in a phosphate buffer (PB) and subsequently cryoprotected in solutions of 10,20 , and $30 \%$ sucrose in PB. Brain blocks were serially cut on a freezing microtome (Leitz Wetzlar) into $50 \mu \mathrm{m}$-thick sections in the parasagittal plane. All sections were collected serially in PB and arranged in six series. The Atlas of Paxinos and Watson (1986) was used to delimit cytoarchitectonic regions of interest. Sections of one series per animal were mounted on gelatin-coated slides, air-dried, and subjected to FJC staining according to Ehara and Ueda (2009). Slides were immersed in a $1 \% \mathrm{NaOH}$ solution (in $80 \%$ ethanol) for $5 \mathrm{~min}$, rinsed for $2 \mathrm{~min}$ in $70 \%$ ethanol, and for $2 \mathrm{~min}$ in distilled water, and then incubated in $0.06 \%$ potassium permanganate solution for $5 \mathrm{~min}$. After water washing ( $2 \mathrm{~min}$ ), the slides were immersed in a FJC solution $(0.0001 \%)$ in $0.1 \%$ acetic acid for $10 \mathrm{~min}$ followed by washing in distilled water. The slides were air-dried on a slide warmer at $50^{\circ} \mathrm{C}$ for $30 \mathrm{~min}$, cleared in xylene, cover slipped with Entellan (Merck). As a positive control for FJC labeling we used brain sections of rats previously treated with the mitochondrial toxin 3-Nitropropionic Acid (3-NP) which induces striatal neurodegeneration. The animals treated with 3NP were from another study not related to the present work. As a better positive control for FJC labeling in the SN, we used also brain sections of animals which previously received intracerebral injections of pilocarpine in order to induce epilepticus status. The number of FJC-positive neurons was analyzed in the CS and SN in six animals of $\mathrm{C}$ and EF2 groups at the stereotaxic coordinate identified as corresponding approximately to lateral $1.9 \mathrm{~mm}$ (plate 81) according to Paxinos and Watson (1986).

Double fluorescence staining against FJC and tyrosine hydroxylase in brain sections of two EF2 animals was achieved by the method described by Ehara and Ueda (2009). Tissue sections were incubated first with blocking solution containing 1\% BSA, $0.3 \%$ triton $\mathrm{X}-100$ for $60 \mathrm{~min}$ and then with rabbit polyclonal anti-TH antibody (1:500; Millipore) for $24 \mathrm{~h}$ at $4^{\circ} \mathrm{C}$. The sections were washed three times in phosphate buffer $(\mathrm{PB}) 0.1 \mathrm{M}$, $\mathrm{pH} 7.4$, and incubated for $4 \mathrm{~h}$ with Rhodamine-conjugated 546labeled anti-rabbit IgG (1:600; Jackson). After washing twice in
$\mathrm{PB}$, they were mounted onto gelatin coated slides and dried at $50^{\circ} \mathrm{C}$ for $30 \mathrm{~min}$. The samples were rehydrated for $1 \mathrm{~min}$, incubated in $0.06 \%$ potassium permanganate solution for $5 \mathrm{~min}$, and then rinsed for $1 \mathrm{~min}$ in distilled water followed by FJC $(0.0001 \%$ dissolved in $0.1 \%$ acetic acid) for $30 \mathrm{~min}$. After rinsed in distilled water, the sections were dried at $50^{\circ} \mathrm{C}$ for $20 \mathrm{~min}$, clearead in xylene for $1 \mathrm{~min}$ and coverslipped with Entellan. Fluoro-Jade $\mathrm{C}$ and $\mathrm{TH}$ in the $\mathrm{CS}$ and $\mathrm{SN}$ were analyzed using an epifluorescence microscope (Leica, DM LB).

\section{FATTY ACID DETERMINATION IN THE CORPUS STRIATUM AND MIDBRAIN}

The fatty acid profiles of CS and midbrain phospholipids were assessed in F1 groups at 95 days and F2 groups at 35 days of age. The pups ( $n=6$ /group) were decapitated and the regions containing the CS or midbrain were rapidly dissected in an ice bath. The tissues were homogenized in a $50 \mathrm{mM}$ Tris- $\mathrm{HCl}$ buffer $(\mathrm{pH}=7.4)$ with EGTA and centrifuged for $30 \mathrm{~min}$ at $28,000 \mathrm{~g}$ at $4^{\circ} \mathrm{C}$. The pellets were immediately re-suspended in $50 \mathrm{mM}$ Tris- $\mathrm{HCl}$ buffer $(\mathrm{pH}=7.4)$. The total lipids of CS or midbrain homogenates were extracted according to Folch et al. (1957). The phospholipids were then separated by means of a Sep-Pak procedure (Juaneda and Rocquelin, 1985) and transmethylated (Berry et al., 1965). These samples were analyzed using a Shimatzu GC apparatus equipped with a flame ionization detector and HPinowax $20 \mathrm{M})$ capillary column $(30 \mathrm{~m} \times 0.32 \mathrm{~mm} \times 0.3 \mu \mathrm{m})$. The column temperature was initially $40^{\circ} \mathrm{C}$ for $1 \mathrm{~min}$, then increased to $150^{\circ} \mathrm{C}$ by $55^{\circ} \mathrm{C} / \mathrm{min}$, and finally increased to $220^{\circ} \mathrm{C}$ by $1.7^{\circ} \mathrm{C} / \mathrm{min}$. The injector and detector temperatures were 200 and $220^{\circ} \mathrm{C}$, respectively. Hydrogen was used as the carrier gas at a flow rate of $1.0 \mathrm{~mL} / \mathrm{min}$; injection was in split-less mode and the injection volume was $1.0 \mu \mathrm{L}$ of the sample isoctane extract. A standard fatty acid methyl ester mixture (Supelco ${ }^{\mathrm{TM}}$, 37 Component FAME mix, USA) was used to identify the fatty acid methyl esters by their retention time. Fatty acid data were expressed as percentage of total peak area. Data are expressed as the mean \pm standard deviation (SD). Differences between the groups were analyzed by Student's $t$-test and considered significant at $P<0.05$.

\section{RESULTS}

Data on body weights of F1 and F2 groups are presented in Table 3. Adult animals of the EF1 group and young animals of the EF2 group showed significantly lower body weights when compared to the control $(p<0.05)$.

Table 3 | Body weights of F1 and F2 animals.

\begin{tabular}{lcc}
\hline Groups & Body Weight (g) & \\
\hline CF1 & $402.54 \pm 40.04$ & $(n=38)$ \\
EF1 & $376.97 \pm 36.92^{* *}$ & $(n=43)$ \\
CF2 & $79.65 \pm 14.87$ & $(n=33)$ \\
EF2 & $71.91 \pm 10.09^{*}$ & $(n=43)$ \\
\hline
\end{tabular}

Values are expressed as Mean $\pm S D$.

${ }^{*} P<0.05 ;{ }^{* *} P<0.01$ Unpaired Student's t-test. 


\section{CORPUS STRIATUM AND MIDBRAIN FATTY ACID PROFILE}

Table 4 shows the midbrain fatty acid profile of F1 generation adult animals and Table 5 combines data of midbrain and CS fatty acids of the F2 generation young animals raised under either control or experimental diets. As can be observed, the midbrain phospholipids from the EF1 and EF2 groups exhibit, respectively, 28 and 50\% lower DHA levels (22:6n-3) as compared to their control groups. DHA levels were also lower in the EF2-CS phospholipids $(\sim 50 \%)$ when compared to control. The reduced levels of DHA in both EF1 and EF2 groups was accompanied by a significant increase in the docosapentanoic fatty acid (DPA; 22:5n6) contents (2-tail $t$-test, $P<0.001)$. On the other hand, the values

Table 4 | Fatty acid composition (\% of total) in midbrain phospholipids of F1 generation groups raised on Control or Experimental diets.

\begin{tabular}{lcc}
\hline Fatty acid & \multicolumn{2}{c}{ Midbrain } \\
\cline { 2 - 3 } & Control diet & Experimental diet \\
\hline C16 & $16.41 \pm 1.9$ & $15.85 \pm 0.81$ \\
C16:1 & $0.96 \pm 0.34$ & $1.10 \pm 0.28$ \\
C18 & $22.47 \pm 1.63$ & $23.99 \pm 1.87$ \\
C18:1n9 & $24.55 \pm 0.96$ & $24.64 \pm 2.00$ \\
C20 & $0.74 \pm 0.13$ & $0.91 \pm 0.10$ \\
C20:1 & $2.04 \pm 0.21$ & $2.83 \pm 0.12$ \\
C20:4n6 & $8.76 \pm 0.32$ & $8.73 \pm 0.30$ \\
C20:3n6 & $0.45 \pm 0.30$ & $0.35 \pm 0.24$ \\
C22 & $0.97 \pm 0.53$ & $0.80 \pm 0.11$ \\
C23 & $3.11 \pm 0.51$ & $3.10 \pm 0.52$ \\
C22:5n6 & $1.03 \pm 0.74$ & $3.16 \pm 0.75^{* *}$ \\
C22:6n3 & $14.41 \pm 1.81$ & $11.25 \pm 0.69$ \\
C24:1n & $2.24 \pm 0.52$ & $1.07 \pm 0.18$ \\
& &
\end{tabular}

Values are expressed as means $\pm S D$.

${ }^{* *} p<0.01 ;{ }^{* *} p<0.001$. for AA (20:4n-6) did not differ between both groups of F1 or F2 generations. With respect to saturated and monounsaturated fatty acids, the presence of coconut oil in the maternal diet significantly increased the levels of palmitic (16:0), stearic (18:0), palmitoleic (16:1), and oleic (18:1n9) acids (2-tail $t$-test, $P<0.01)$ in the EF2 midbrain phospholipids.

\section{LIPID PEROXIDATION AND T-SOD ENZYME ACTIVITY IN ADULT ANIMALS OF F1 GENERATION}

Biochemical results of the F1 groups are summarized in Figure 1. As expected, LP (measured as TBARS levels) was found to be significantly increased in $\mathrm{SN}(0.770 \pm 0.136 \mathrm{nmol}$ $\mathrm{MDA} / \mathrm{mg}$ protein) and CS $(0.834 \pm 0.140 \mathrm{nmol} \mathrm{MDA} / \mathrm{mg}$ protein) homogenates of CF1 group previously treated with $30 \mu \mathrm{M}$ SNP, compared to the control condition $(0.425 \pm 0.105$ and $0.532 \pm 0.015 \mathrm{nmol} \mathrm{MDA} / \mathrm{mg}$ protein for $\mathrm{SN}$ and $\mathrm{CS}$, respectively; $P<0.001)$. However, TBARS levels in both regions were not modified in rats fed on the experimental diet $(0.494 \pm$ 0.089 and $0.570 \pm 0.038 \mathrm{nmol} \mathrm{MDA} / \mathrm{mg}$ protein for SN and CS, respectively) when compared to the control animals (Figure 1A). Consistent with these results, a significant increase in the t-SOD enzyme activity was observed in the EF1 group $(P<0.01)$ either in the $\mathrm{SN}(0.735 \pm 0.020 \mathrm{U} / \mathrm{mg}$ protein $)$ or CS $(0.640 \pm 0.192$ $\mathrm{U} / \mathrm{mg}$ protein) compared to the control condition not submitted to pre-treatment with SNP $(0.606 \pm 0.028$ and $0.355 \pm$ $0.034 \mathrm{U} / \mathrm{mg}$ protein for $\mathrm{SN}$ and $\mathrm{CS}$, respectively). As can be observed, the SNP treatment used as a positive control, significantly increased SOD activity in the SN $(1.241 \pm 0.206 \mathrm{U} / \mathrm{mg}$ protein) and CS (1.832 $\pm 0.046 \mathrm{U} / \mathrm{mg}$ protein).

\section{LIPID PEROXIDATION, T-SOD, AND CAT ENZYME ACTIVITIES IN YOUNG ANIMALS OF F2 GENERATION}

In young animals of the F2 generation, distinct effects were induced by the experimental diet in the two regions analyzed. Evidence of LP, assessed by a significant increase in TBARS levels, was detected in the SN of EF2 group $(0.564 \pm$

Table 5 | Fatty acid composition (\% of total) in Corpus Striatum and Midbrain membrane phospholipids of F2 generation groups raised on Control or Experimental diets.

\begin{tabular}{|c|c|c|c|c|}
\hline \multirow[t]{2}{*}{ Fatty acid } & \multicolumn{2}{|c|}{ Corpus Striatum } & \multicolumn{2}{|c|}{ Midbrain } \\
\hline & Control diet & Experimental diet & Control diet & Experimental diet \\
\hline C16 & $17.99 \pm 1.04$ & $21.74 \pm 0.74$ & $16.51 \pm 1.90$ & $24.09 \pm 0.27^{*}$ \\
\hline C16:1 & $0.73 \pm 0.10$ & $0.73 \pm 0.12$ & $0.64 \pm 0.04$ & $0.85 \pm 0.03$ \\
\hline C17 & $\mathrm{Nd}$ & nd & $0.16 \pm 0.00$ & $0.20 \pm 0.02$ \\
\hline C18 & $25.74 \pm 0.25$ & $25.20 \pm 0.51$ & $24.88 \pm 0.67$ & $29.09 \pm 0.37^{*}$ \\
\hline C18:1n9 & $17.07 \pm 0.34$ & $15.18 \pm 0.69$ & $16.38 \pm 0.25$ & $19.21 \pm 0.21^{*}$ \\
\hline C18:2n6t & nd & nd & $0.74 \pm 0.17$ & $0.65 \pm 0.22$ \\
\hline C20:1 & nd & nd & $0.62 \pm 0.10$ & $0.60 \pm 0.05$ \\
\hline C20:4n6 (AA) & $14.08 \pm 0.27$ & $13.12 \pm 0.34$ & $13.74 \pm 0.83$ & $14.93 \pm 0.48$ \\
\hline C23 & $3.88 \pm 0.13$ & $3.46 \pm 0.18$ & $3.98 \pm 0.20$ & $3.52 \pm 0.19$ \\
\hline $\mathrm{C} 22: 5 \mathrm{n} 6$ & $1.54 \pm 0.06$ & $9.60 \pm 0.26^{* *}$ & $1.49 \pm 0.11$ & $9.39 \pm 0.31^{* *}$ \\
\hline C22:6n3 (DHA) & $19.23 \pm 0.88$ & $9.48 \pm 0.84^{* *}$ & $19.70 \pm 0.69$ & $8.70 \pm 0.73^{* *}$ \\
\hline
\end{tabular}

Values are expressed as means $\pm S D$.

${ }^{*} p<0.01 ;{ }^{*} p<0.001 ;$ nd, not detected. 


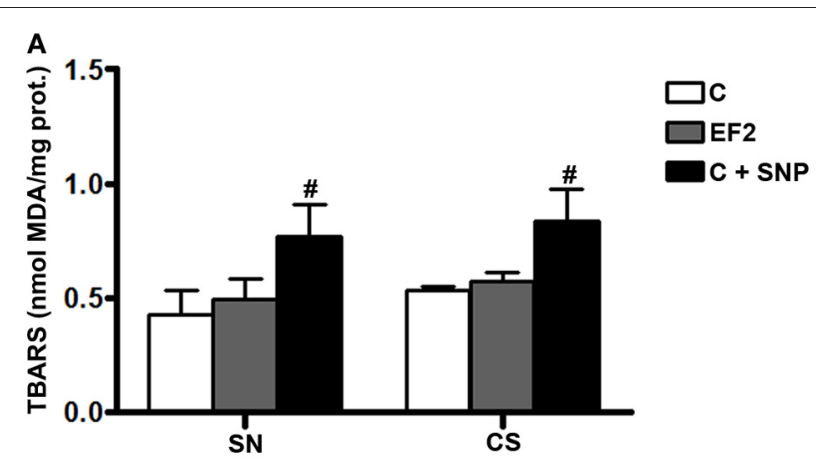

B

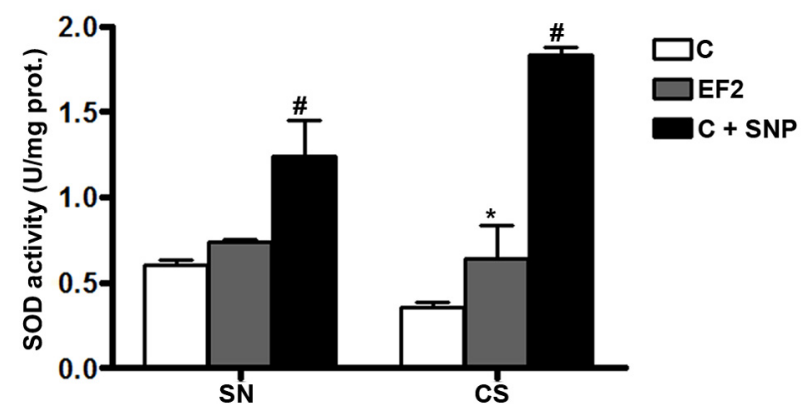

FIGURE 1 | Thiobarbituric acid-reactant substances (TBARS) levels (A) and total superoxide dismutase (t-SOD) activities (B) in the pool of Substantia Nigra and Corpus Striatum from first generation adult rats fed essential fatty acid restricted diet and controls ( $n=12$ per group). * $P<0.05$ compared to control group. Treatment of control homogenates with sodium nitroprusside (SNP) was used as positive control in all the experiments. $\# P<0.001$ compared to control or EF1 groups.

$0.02 \mathrm{nmol} \mathrm{MDA} / \mathrm{mg}$ protein) in comparison with the control group $(0.372 \pm 0.01 \mathrm{nmol} \mathrm{MDA} / \mathrm{mg}$ protein, $P<0.05)$. The magnitude of LP induced by the experimental condition in the $\mathrm{SN}$ is about $50 \%$ less than that obtained by using $30 \mu \mathrm{M}$ SNP $(1.330 \pm 0.220 \mathrm{nmol} \mathrm{MDA} / \mathrm{mg}$ protein $)$. No difference between the EF2 $(0.354 \pm 0.005 \mathrm{nmol} \mathrm{MDA} / \mathrm{mg}$ protein $)$ and the $\mathrm{C}$ $(0.391 \pm 0.083 \mathrm{nmol} \mathrm{MDA} / \mathrm{mg}$ protein $)$ groups was found in the CS (Figure 2A). A significant increase in t-SOD enzyme activity was found in the CS of the EF2 group $(1.074 \pm 0.145 \mathrm{U} / \mathrm{mg}$ protein) compared to the control group in the absence of pretreatment with SNP $(0.610 \pm 0.096 \mathrm{U} / \mathrm{mg}$ protein, $P<0.01)$. Nevertheless, the increase in SOD activity in the EF2 group CS was smaller than that induced by $30 \mu \mathrm{M}$ SNP in the $\mathrm{C}$ group $(1.633 \pm 0.046 \mathrm{U} / \mathrm{mg}$ protein). No difference between the groups was detected for t-SOD activity in the SN $(0.741 \pm 0.087$ and $0.667 \pm 0.138 \mathrm{U} / \mathrm{mg}$ protein for the $\mathrm{EF} 2$ and $\mathrm{C}$ groups, respectively) as shown in the Figure 2B. On the other hand, the CAT activity was significantly reduced in the SN of the EF2 group $(0.652 \pm 0.238 \mathrm{nmol} / \mathrm{min} / \mathrm{mg}$ protein $)$ compared to the control group $(3.159 \pm 0.279 \mathrm{nmol} / \mathrm{min} / \mathrm{mg}$ protein in the control; $P<0.001)$. No difference between the groups was detected in CAT activity in the CS $(4.339 \pm 0.217 \mathrm{nmol} / \mathrm{min} / \mathrm{mg}$ protein and $4.420 \pm 0.125 \mathrm{nmol} / \mathrm{min} / \mathrm{mg}$ protein for the EF2 and C groups, respectively) as shown in Figure 2C. The insert in the Figure 2C
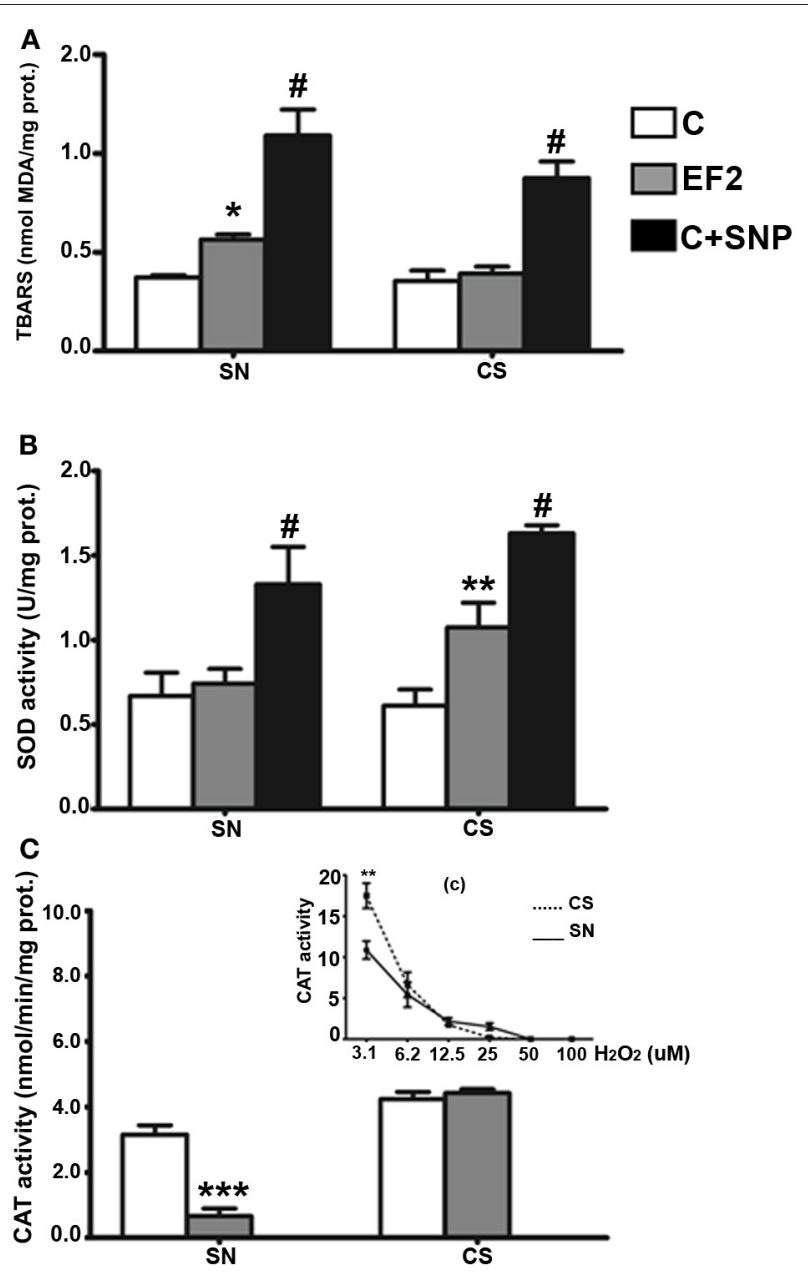

FIGURE 2 | Thiobarbituric acid-reactant substances (TBARS) levels (A), total superoxide dismutase (t-SOD) activities (B), and catalase (CAT) activities (C) in the pool of Substantia Nigra and Corpus Striatum from young rats fed an essential fatty acid restricted diet over two generations and respective controls ( $\boldsymbol{n}=12$ per group). ${ }^{*} P<0.05$; ** $P<0.001$ compared to control group. Treatment of control homogenates with sodium nitroprusside (SNP) was used as positive control for TBARS and t-SOD in all the experiments. The insert (c) in the panel (C) shows the $\mathrm{H}_{2} \mathrm{O}_{2}$ concentration-dependent manner of the CAT activity in the SN and CS control homogenates obtained as positive controls. \#P $<0.0001$ compared to control or EF2 groups.

shows the $\mathrm{H}_{2} \mathrm{O}_{2}$ concentration-dependent manner of the CAT activity in the SN and CS control homogenates obtained as positive controls. As can be observed, at lower concentrations of $\mathrm{H}_{2} \mathrm{O}_{2}$, the CAT activity is significantly greater in the CS as compared to $\mathrm{SN}(p<0.05)$ but this difference disappears at higher concentrations.

\section{FLUORO JADE C AND TYROSINE HYDROXILASE LABELING}

Fluoro-Jade C-positive cell bodies were not detected in the $\mathrm{SN}$ or $\mathrm{CS}$ in the groups (6 animals/group) of F1 generation (Figure 3A). In the $\mathrm{SN}$ of the EF2 group, several FJC-positive cells were seen either in the pars compacta or in the pars reticulata while no 
labeling was detected in cell bodies of the CS in all animals $(n=6)$ analyzed (Figure $3 \mathbf{B})$. In the EF2 group $(n=6)$, the number of FJC-positive cells distributed in the pars compacta and pars reticulata at the middle level of SN changed from 59 to 70 cells and the average number was estimated as $63.8 \pm 6.4$ cells.
Double fluorescence staining for FJC and TH of a representative EF2 animal is shown in the Figure 4. As can be seen, signals of degeneration were detected in $\mathrm{SN}$ dopaminergic and nondopaminergic neurons either in the pars reticulata or in the pars compacta. Nevertheless, no staining for FJC was found in cell

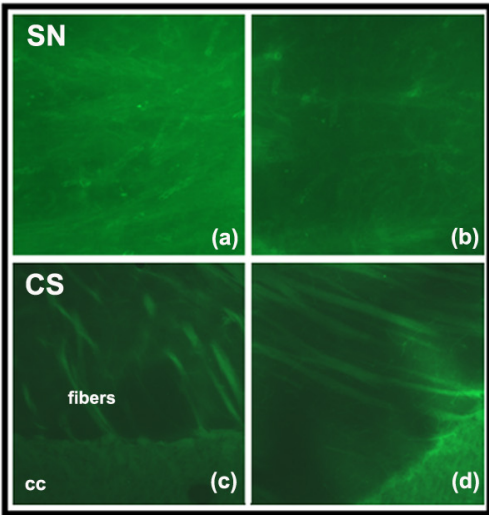

FIGURE 3 | Fluoro-Jade $\mathrm{C}$ staining in brain parasagittal sections of F1- (panel A) or F2- (panel B) generation groups at the level of Substantia nigra (SN) or Corpus Striatum (CS). No labeling was detected in cell bodies or processes of SN $(\mathbf{A a}, \mathbf{A b})$ and $\mathrm{CS}(\mathbf{A c}, \mathbf{A d})$ in adult animals of F1 generation. However, FJC positive cell bodies and processes were detected in the SN pars

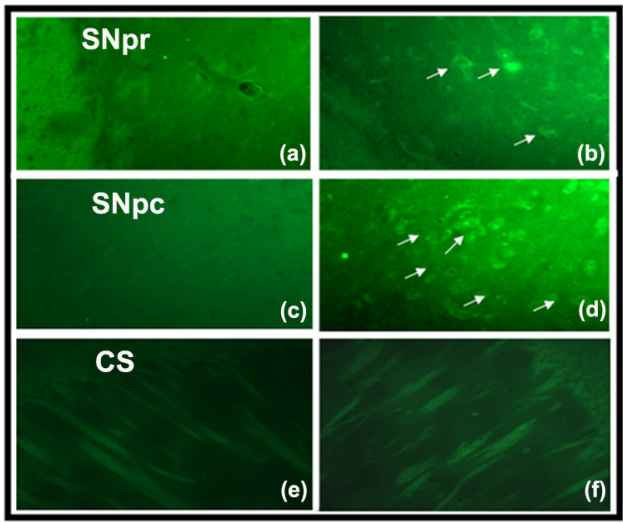

reticulata $\mathbf{( B b}$ ) and pars compacta (Bd) of EF2 group while no labeling in these regions was seen in the controls (Ba, $\mathbf{B c})$. No FJC labeling was detected in cel bodies of the CS in the EF2 (Bf) or control (Be) groups. A slight and non-specific labeling was seen in regions rich in myelin such as cerebral peduncle (cp), corpus callosum (cc), or myelinated fibers crossing the CS.
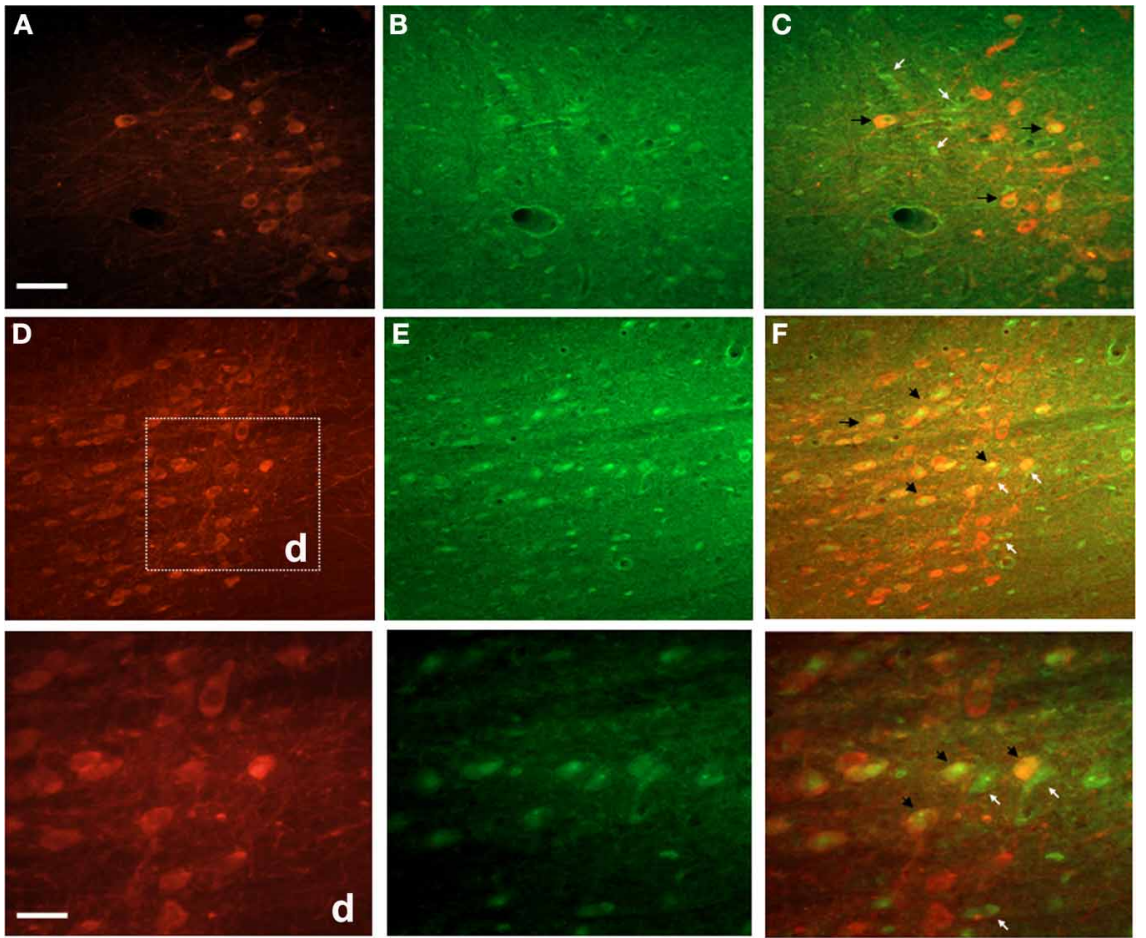

FIGURE 4 | Photographs of epifluorescence microscopy showing SN sections from a representative EF2 animal subjected to TH

immunostaining followed by Fluoro-Jade $\mathbf{C}$ staining. Examples of single (FJC; yellow arrows) or double (TH + FJC; black arrows) labeled cells can be seen either in the SN pars reticulata $(\mathbf{A}, \mathbf{B}$, and $\mathbf{C})$ or in the pars compacta $(\mathbf{D}, \mathbf{E}$, and $\mathbf{F})$. High magnification of the region (d) is shown in the bottom panel. Scale bar of $\mathbf{A}=\mathbf{B}, \mathbf{C}, \mathbf{D}, \mathbf{E}$, and $\mathbf{F}$ represents $60 \mu \mathrm{m}$ while the scale bar of bottom panel represents $20 \mu \mathrm{m}$. 


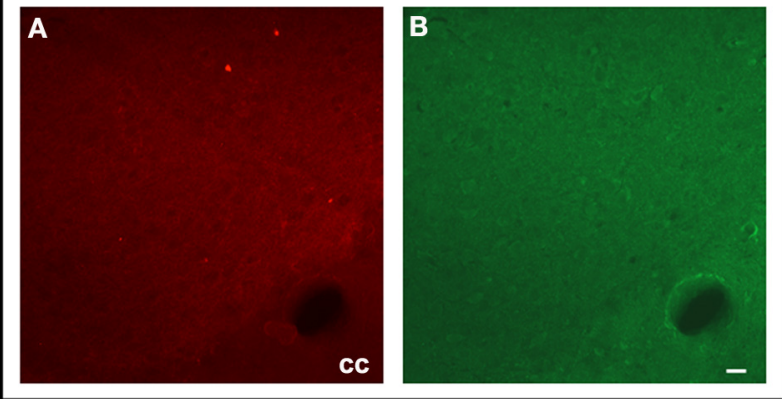

FIGURE 5 | Photographs of epifluorescence microscopy showing CS sections from a representative EF2 animal subjected to $\mathrm{TH}$ immunostaining (A) followed by Fluoro-Jade $\mathbf{C}$ staining (B). Note the absence of FJC-positive cells surrounded by $\mathrm{TH}$-positive neuronal terminals. $\mathrm{cc}=$ corpus calosum, Scale bar $=40 \mu \mathrm{m}$.

bodies surrounded by TH-positive neuronal terminals in the CS, confirming data obtained using single labeling for FJC (Figure 5).

\section{DISCUSSION}

The current study investigated whether a dietary restriction of both linoleic and $\alpha$-linolenic fatty acids for one or two generations could affect the redox balance in the SN and CS. We hypothesized that OS could be a potential mechanism involved in the loss of dopaminergic cells previously demonstrated (Passos et al., 2012). Our data showed signals of degeneration in SN dopaminergic and non-dopaminergic neurons and indicated a differential vulnerability of SN and CS to oxidative insult induced by two generations of EFA dietary restriction.

\section{REPERCUSSION OF DIETARY TREATMENT ON BODY WEIGHT}

The significant lower body weight gain of adult EF1 and young EF2 animals is in agreement with previous studies using coconut oil as the only source of dietary lipids (Deuel et al., 1954; Soares et al., 1995; Borba et al., 2010). Regarding this effect, this type of dietary treatment has been associated with dysfunction of growth hormone regulation (Soares et al., 1995). Moreover, it has been reported that coconut oil can reduce body weight due to high saturated medium chain fatty acids (8:0-14:0) turnover rates, which are predominant in its lipid profile. Such effect seems to be independent of essential fatty acid deficiency (Hargrave et al., 2005).

\section{MIDBRAIN AND CORPUS STRIATUM FATTY ACID PROFILE}

It has been demonstrated that a diet containing coconut oil as the only source of lipids depletes DHA in the brain more than a fat free diet, even for a short-term treatment, especially due to the diet's high content of saturated fatty acids (Ling et al., 2010). In the present study, the experimental diet based on coconut oil significantly reduced DHA levels about 28 and 50\% in the midbrain phospholipids of the EF1 and EF2 groups, respectively, as compared to their controls. The DHA depletion was accompanied by a significant increase in DPA levels, which reinforces the condition of DHA deficiency. On the other hand, despite containing $8 \%$ linoleic acid (about 30\% of recommended minimal dietary requirement for rodents (Bourre et al., 1990), the experimental diet did not modify the AA levels in either region of EF2 group. These results agree with other studies, indicating that AA is more tightly controlled than DHA in the central nervous system and that its brain concentrations are less vulnerable to limitations in the supply of precursor than other organs (Bourre et al., 1990; Brenna and Diau, 2007; Igarashi et al., 2009; Ling et al., 2010). In fact, recent evidence has indicated that even when using a diet containing $2.3 \%$ linoleic acid for 15 weeks, starting at weaning, the brain AA concentration is reduced by only $28 \%$, while a $74 \%$ reduction has been observed in the liver of the same rats (Igarashi et al., 2009). Thus, in addition to DHA deficiency, our dietary treatment was able to increase AA/DHA ratio in the fatty acid profile of SN and CS phospholipids.

\section{REPERCUSSION OF DIETARY TREATMENT ON LIPID PEROXIDATION AND ENZYMATIC ANTI-OXIDANT ACTIVITY}

It has been established that an imbalance in the AA/DHA ratio and especially DHA deficiency can decrease anti-inflammatory and anti-oxidant responses and induce cellular damage in different classes of neurons (Yavin, 2006; Schmitz and Ecker, 2008). An inverse relation between the number of some brain neurons and increasing ratios of $n-6 / n-3$ EFAs in the maternal diet has been also recently reported (Tian et al., 2011). In the present study, an increase in the t-SOD activity observed in the SN and CS of the EF1 group was able to protect these regions from membrane LP measured as TBARS levels. The absence of FJC labeling in neuronal cell bodies of both brain regions reinforces these results, considering the efficacy of this reagent in detecting signals of neurodegeneration induced by conditions of OS, such as ischemia (Yang et al., 2011), glutamate excitotoxicity (Ehara and Ueda, 2009) or dopaminergic lesions induced by 6-OHDA (Ehara and Ueda, 2009) or MPTP (Bian et al., 2007; Li et al., 2009).

EFA dietary restriction over two generations, which induced a more expressive DHA deficiency in midbrain phospholipids $(\sim 50 \%)$ and AA/DHA ratio $(\sim 2)$, was able to provoke LP and impaired the anti-oxidant responses at least in SOD and CAT enzymes in the SN of the EF2-group as compared to the control. Such results are consistent with recent evidence of the protective action of DHA dietary supplementation on SN cell populations under experimental conditions that induce OS, such as MPTP (Ozsoy et al., 2011). The lack of efficient t-SOD reactivity and the expressive reduction in the CAT activity observed in the EF2 group shows the vulnerability of $\mathrm{SN}$ to conditions that reduce DHA availability during the critical period of brain development. Studies on rats or human SN have indicated a progressive decrease in the activity of several anti-oxidant enzymes including SOD and CAT during physiological brain aging (Kolosova et al., 2003; Venkateshappa et al., 2012). The present findings in the EF2 young animals corroborate our initial hypothesis indicating that a decreased anti-oxidant function can be a potential mechanism by which long-term EFA dietary restriction induces loss of SN dopaminergic neurons (Passos et al., 2012). Thus, increased levels of OS in the young brain might act synergistically with other deleterious effects induced by DHA deficiency, accelerating the degenerative profile of SN. The FJC staining in the SN of EF2 animals reinforces these data, demonstrating the presence of 
neuronal damage in several dopaminergic neurons either in the pars compacta or in the pars reticulata. Moreover, we also detected signals of degeneration in non-dopaminergic cells at the same regions of $\mathrm{SN}$, suggesting that the oxidative insult induced by EFA dietary restriction affects neuronal populations with distinct neurochemical profile.

In contrast to the effects detected in the $\mathrm{SN}$ and despite a similar DHA deficiency, we did not observe LP or anti-oxidant dysfunction in the CS of the EF2 young rat brains, when compared to their respective controls. In support of this biochemical data, we did not find FJC-positive cell bodies in parasagittal or transversal sections of this nucleus. These findings reinforce some early and recent evidence in human and experimental animals that this region is more resistant than $\mathrm{SN}$ under physiological (Kolosova et al., 2003; Venkateshappa et al., 2012) or pathological conditions where $\mathrm{SN}$ dopaminergic neurons are affected (Floor and Wetzel, 1998; Mythri et al., 2011). The significant increase in the t-SOD activity in the CS of the EF2 animals indicates that this region has differential compensatory means which can be triggered from the insult induced by DHA deficiency. It is noteworthy that under normal conditions, dietary DHA supplementation, even for a short period (30 days), is able to increase the t-SOD activity in the CS of adult rats, which has been suggested as a potential regulatory action of this LC-PUFA on this enzyme (Sarsilmaz et al., 2003). If this is the case, our findings suggest that such action could be activated even under conditions of 50\% DHA depletion in the CS phospholipids. A differential reactivity of CS under OS conditions was also recently reported: in animals injured with 6-OHDA, the dopamine turnover is significantly increased in this nucleus by fish oil supplementation (Delattre et al., 2010).

The increased t-SOD activity in the CS was not accompanied by a similar CAT reaction, which did not change its activity as compared to the control condition. These enzymes play complementary activities in the anti-oxidative defense system, considering that the $\mathrm{H}_{2} \mathrm{O}_{2}$ generated by SOD activity is the substrate for CAT. Thus, the absence of LP in the CS suggests that other antioxidant mechanisms involved in the degradation of $\mathrm{H}_{2} \mathrm{O}_{2}$ could be implicated in the relative resistance of this nucleus. An expressive increase in the total glutathione levels and in the glutathione peroxidase activity associated with glial cell proliferation has been found in the CS and frontal cortex of human postmortem PD brains (Mythri et al., 2011). Although future studies need to be carried out in order to address this issue in our experimental model, preliminary results of our group indicate that the glial cell reactivity might be also implicated in the lower vulnerability of CS to oxidative insult described herein.

\section{REFERENCES}

Aebi, H. (1984). Catalase in vitro. Methods Enzymol. 105, 121-126.

Ahmad, S. O., Park, J. H., Radel, J. D., and Levant, B. (2008). Reduced numbers of dopamine neurons in the substantia nigra pars compacta and ventral tegmental area of rats fed an n-3 polyunsaturated fatty acid-deficient diet: a stereological study. Neurosci. Lett. 438, 303-307.

Berry, J. F., Cevallos, W. H., and Wade, R. R. (1965). Lipid class and fatty acid composition of intact peripheral nerve and during Wallerian degeneration. J. Am. Oil Chem. Soc. 42, 492-500.

Bian, G. L., Wei, L. C., Shi, M., Wang, Y. Q., Cao, R., and Chen, L. W. (2007).

Despite the resistance of CS to OS under the present experimental conditions, we cannot discard potential effects of EFA dietary restriction on other parameters involving neuroprotection in the nigrostriatal system. The anti-oxidant parameters here investigated under conditions of DHA deficiency probably are not working alone. A recent study demonstrated that a relatively short-term feeding of an $\alpha$-linolenic acid-restricted diet was able to lower the DHA content and the brain derived neurotrophic factor (BDNF) levels in the mouse striatum, while two other brain regions were not affected (Miyazawa et al., 2010). Conversely, when DHA is supplemented in the diet, CS strongly reacts to OS induced by MPTP, increasing the synthesis of BDNF more than in control conditions (Bousquet et al., 2009). The disrupted relation between OS and neurotrophin availability could be involved in behavioral or neurochemical effects observed in animals or human beings submitted to EFA dietary restriction (Fedorova and Salem, 2006; Kuperstein et al., 2008).

\section{CONCLUSION}

The present data shows the importance of adequate dietary levels of EFA to maintain an effective redox balance in the SN. Our results demonstrate that LP associated with an impaired anti-oxidant response increases the vulnerability of SN dopaminergic and non-dopaminergic neurons to degeneration induced by long-term EFA dietary restriction. These results reinforce the hypothesis that this dietary treatment increases the risk of certain neurological disorders. The data also demonstrate that biological mechanisms of resilience can be activated in the CS even under a similar condition of DHA deficiency.

\section{ACKNOWLEDGMENTS}

The authors are grateful to Zenira C. Xavier for technical assistance, to Dr. Ranilson de Souza Bezerra and Dr. Marcelo Guerra for the permission to use equipment in the laboratory of Enzymology and Vegetal Cytogenetic, respectively. The contributions of Dr. Sidney Pratt and Dr. John D. Bousfield for reviewing the English version of the text are gratefully appreciated. The acquisition of the reagents used in this work was supported by the financial support from Pro-Reitoria de Pesquisa da Universidade Federal de Pernambuco (PROPESQ, UFPE), the Brazilian National Research Council (CNPq; Projeto Casadinho \# 620248/2004-1); CAPES (PROCAD \# 0008052/2006 and PROCAD NF-2010), FINEP/IBN-Net. (\# 01.06.0842-00). We are grateful to Fundação de Amparo à Ciência e Tecnologia do Estado de Pernambuco (FACEPE) which provided scholarships for Henriqueta Dias Cardoso, David Filipe de Santana, and Rafael Salomé de Oliveira.

Fluoro-Jade C can specifically stain the degenerative neurons in the substantia nigra of the 1-methyl-4phenyl-1 23, 6-tetrahydro pyridinetreated C57BL/6 mice. Brain Res. 30, 55-61.

Borba, J. M. C., Rocha-de-Melo, A. P., Amâncio dos Santos, A., Andrade da Costa, B. L. S., and Silva, R. P. (2010). Essential fatty acid deficiency reduces cortical spreading depression propagation in rats: a two-generation study. Nutr. Neurosci. 13, 144-150.

Bourre, J. M., Piciotti, M., Dumont, O., Pascal, G., and Durand, G. (1990). Dietary linoleic acid and polyunsaturated fatty acids in rat brain and other organs: minimal requirements of linoleic acid. Lipids 25, 465-472. 
Bousquet, M., Gibrat, C., Saint-Pierre, M., Julien, C., and Calon, F. (2009). Modulation of brain-derived neurotrophic factor as a potential neuroprotective mechanism of action of omega-3 fatty acids in a parkinsonian animal model. Prog. Neuropsychopharmacol. Biol. Psychiatry 33, 1401-1408.

Bousquet, M., Saint-Pierre, M., Julien, C., Salem, N. Jr., and Cicchetti, F. (2008). Beneficial effects of dietary omega- 3 polyunsaturated fatty acid on toxin-induced neuronal degeneration in an animal model of Parkinson's disease. FASEB J. 22, 1213-1225.

Brenna, J. T., and Diau, G. Y. (2007). The influence of dietary docosahexaenoic acid and arachidonic acid on central nervous system polyunsaturated fatty acid composition. Prostaglandins Leukot. Essent. Fatty Acids 77, 247-250.

Cansev, M., Ulus, I. H., Wang, L., Maher, T. J., and Wurtman, R. J. (2008). Restorative effects of uridine plus docosahexaenoic acid in a rat model of Parkinson's disease. Neurosci. Res. 62, 206-209.

Delattre, A. M., Kiss, A., Szawka, R. E., Anselmo-Franci, J. A., Bagatini, P. B., Xavier, L. L., Rigon, P., Achaval, M., Iagher, F., de David, C., Marroni, N. A., and Ferraz, A. C. (2010). Evaluation of chronic omega-3 fatty acids supplementation on behavioral and neurochemical alterations in 6-hydroxydopamine-lesion model of Parkinson's disease. Neurosci. Res. 66, 256-264.

Deuel, H. J., Alfin-Slater Jb, E. B., Wells, A. F., Krydeh, G. D., and Aftergood, L. (1954). The effect of fat level of the diet on general nutrition. XIV. Further studies of the effect of hydrogenated coconut oil on essential fatty acid deficiency in the Rat. J. Nutr. 55, 337-346.

Ehara, A., and Ueda, S. (2009). Application of fluoro-jade C in acute and chronic neurodegeneration models: utilities and staining differences. Acta Histochem. Cytochem. 42, 171-179.

Fedorova, I., and Salem, N. Jr. (2006). Omega-3 fatty acids and rodent behavior. Prostaglandins Leukot. Essent. Fatty Acids 75, 271-289.

Floor, E., and Wetzel, M. G. (1998). Increased protein oxidation in human substantia nigra pars compacta in comparison with basal ganglia and prefrontal cortex measured with an improved dinitrophenylhydrazine assay. $J$. Neurochem. 70, 268-275.
Folch, J., Lees, M., and Sloane Stanley, G. H. (1957). A simple method for the isolation and purification of total lipids from animal tissues. $J$. Biol. Chem. 226, 497-509.

Glozman, S., Green, P., and Yavin, E. (1998). Intraamniotic ethyl docosahexaenoate administration protects fetal rat brain from ischemic stress. J. Neurochem. 70, 2484-2491.

Green, P., Glozman, S., Weiner, L., and Yavin, E. (2001). Enhanced free radicals scavenging and decreased lipid peroxidation in the rat fetal brain after treatment with ethyl-docosahexaenoate. Biochim. Biophys. Acta 1532, 203-212.

Hargrave, K. M., Azain, M. J., and Miner, J. L. (2005). Dietary coconut oil increases conjugated linoleic acid-induced body fat loss in mice independent of essential fatty acid deficiency. Biochim. Biophys. Acta 1737, 52-60.

Hashimoto, M., and Hossain, S. (2011). Neuroprotective and ameliorative actions of polyunsaturated fatty acids against neuronal diseases: beneficial effect of docosahexaenoic acid on cognitive decline in Alzheimer's disease. J. Pharmacol. Sci. 116, 150-162.

Igarashi, M., Gao, F., Kim, H. W., Ma, K., Bell, J. M., and Rapoport, S. I. (2009). Dietary n-6 PUFA deprivation for 15 weeks reduces arachidonic acid concentrations while increasing n-3 PUFA concentrations in organs of post-weaning male rats. Biochim. Biophys. Acta 132-139.

Jenner, P., Dexter, D. T., and Sian, J. (1992). Oxidative stress as a cause of nigral cell death in Parkinson's disease and incidental Lewy body disease. The royal kings and queens Parkinson's disease research group. Ann. Neurol. 32(Suppl.), S82-S87.

Juaneda, P., and Rocquelin, G. (1985). Rapid and convenient separation of phospholipids and nonphosphorus lipids from rat heart using silica cartridges. Lipids 20, 40-41.

Kidd, P. M. (2000). Parkinson's disease as multifactorial oxidative neurodegeneration: implications for integrative management. Altern. Med. Rev. 5, 502-545.

Kitajka, K., Sinclair, A. J., Weisinger, R. S., Weisinger, H. S., and Mathai, M. (2004). Effects of dietary omega-3 polyunsaturated fatty acids on brain gene expression. Proc. Natl. Acad. Sci. U.S.A. 101, 10931-10936.

Kohen, R., and Nyska, A. (2002). Invited review: oxidation of biological systems: oxidative stress phenomena, anti-oxidants, redox reactions, and methods for their quantification. Toxicol. Pathol. 30, 620-650.

Kolosova, N. G., Shcheglova, T. V., Amstislavskaya, T. G., and Loskutova, L. V. (2003). Comparative analysis of LPO products in brain structures of Wistar and OXYS rats of different age. Bull. Exp. Biol. Med. 135, 593-596.

Kuperstein, F., Eilam, R., and Yavin, E. (2008). Altered expression of key dopaminergic regulatory proteins in the postnatal brain following perinatal $n-3$ fatty acid dietary deficiency. J. Neurochem. 106, 662-671.

Lapillonne, A., Clarke, S. D., and Heird, W. C. (2004). Polyunsaturated fatty acids and gene expression, Curr. Opin. Clin. Nutr. Metab. Care 2, 151-156.

Li, L. H., Qin, H. Z., Wang, J. L. Wang, J., Wang, X. L., and Gao, G. D. (2009). Axonal degeneration of nigra-striatum dopaminergic neurons induced by 1-methyl- 4 phenyl-1, 2, 3, 6-tetrahydropyridine in mice. J. Int. Med. Res. 37, 455-463.

Ling, P. R., De Leon, C. E., Le, H., Puder, M., and Bistrian, B. R. (2010). Early development of essential fatty acid deficiency in rats: fatfree vs. hydrogenated coconut oil diet. Prostaglandins Leukot. Essent. Fatty Acids 83, 229-237.

Marcheselli, V. L., Hong, S., and Lukiw, W. J. (2003). Novel docosanoids inhibit brain ischemia-reperfusionmediated leukocyte infiltration and pro-inflammatory gene expression. J. Biol. Chem. 278, 43807-43817.

Mayurasakorn, K., Williams, J. J., Ten, V. S., and Deckelbaum, R. J. (2011). Docosahexaenoic acid: brain accretion and roles in neuroprotection after brain hypoxia and ischemia. Curr. Opin. Clin. Nutr. Metab. Care $14,158-167$.

Melo, A., Monteiro, L., Lima, R. M. Oliveira, D. M., Cerqueira, M. D., and El-Bachá, R. S. (2011) Oxidative stress in neurodegenerative diseases: mechanisms and therapeutic perspectives. Oxid. Med. Cell. Longev. 2011, 14

Misra Hara, P., and Fridovich, I. (1972). The role of superoxide anion in the autoxidation of epinephrine and a simple assay for superoxide dismutase. J. Biol. Chem. 247, 3170-3175.

Miyazawa, D., Yasui, Y., Yamada, K., Ohara, N., and Okuyama, H. (2010). Regional differences of the mouse brain in response to an $\alpha$-linolenic acid-restricted diet: neurotrophin content and protein kinase activity. Life Sci. 87, 490-494.
Mukherjee, P. K., Marcheselli, V. L., Serhan, C. N., and Bazan, N. G. (2004). Neuroprotectin D1, a docosahexaenoic acid derived docosatriene protects human retinal pigment epithelial cells from oxidative stress. Proc. Natl. Acad. Sci. U.S.A. 101, 8491-8496.

Mythri, R. B., Venkateshappa, C., Harish, G., Mahadevan, A., Muthane, U. B., Yasha, T. C., Bharath, M. M. S., and Shankar, S. K. (2011). Evaluation of markers of oxidative stress, anti-oxidant function and astrocytic proliferation in the striatum and frontal cortex of Parkinson's disease brains. Neurochem. Res. 36, 1452-1463.

Ohkawa, H., Ohishi, N., and Yagi, K. (1979). Assay for lipid peroxides in animal tissues by thiobarbituric acid reaction. Anal. Biochem. 95, 351-358.

Ozsoy, O., Tanriover, G., Derin, N. Uysal, N., and Demir, N. (2011). The effect of docosahexaenoic Acid on visual evoked potentials in a mouse model of Parkinson's disease: the role of cyclooxygenase- 2 and nuclear factor kappa-B. Neurotox. Res. 20, 250-262.

Pan, H. C., Kao, T. K., Ou, Y. C., Yang, D. Y., Yen, Y. J., Wang, C. C., Chuang, Y. H., Liao, S. L., Raung, S. L., Wu, C. W., Chiang, A. N., and Chen, C. J. (2009). Protective effect of docosahexaenoic acid against brain brain injury in ischemic rats. J. Nutr. Biochem. 20, 715-725.

Passos, P. P., Borba, J. M. C., Rocha de Melo, A. P., Guedes, R. C. A., Silva, R. P., Melo Filho, W. T., Gouveia, K. M. M., Navarro, D. M. A. F., Santos, G. K. N., Borner, R., Picanço-Diniz, C. W., Pereira, A. Jr., Costa, M. S. M. O., Rodrigues, M. C. A., and Andrade-da-Costa, B. L. S. (2012). Dopaminergic cell populations of the rat substantia nigra are differentially affected by essential fatty acid dietary restriction over two generations. J. Chem. Neuroanat. 44 66-75.

Paxinos, G., and Watson, C. (1986). The Rat Brain in Stereotaxic Coordinates. California: Academic Press Inc.

Rotstein, N. P., Politi, L. E., German, O. L., and Girotti, R. (2003). Protective effect of docosahexaenoic acid on oxidative stress-induced apoptosis of retina photoreceptors. Invest. Ophthalmol. Vis. Sci. 44, 2252-2259.

Sarsilmaz, M., Songur, A., Ozyurt, H., Kuş, I., Ozen, O. A., Ozyurt, B., Söğüt, S., and Akyol, O. (2003). Potential role of dietary omega3 essential fatty acids on some 
oxidant/anti-oxidant parameters in rats' corpus striatum. Prostaglandins Leukot. Essent. Fatty Acids 69, 253-259.

Sayre, L. M., Smith, M. A., and Perry, G. (2001). Chemistry and biochemistry of oxidative stress in neurodegenerative disease. Curr. Med. Chem. 8, 721-738.

Schmitz, G., and Ecker, J. (2008). The opposing effects of $\mathrm{n}-3$ and $\mathrm{n}$ 6 fatty acids. Prog. Lipid Res. 47, 147-155.

Soares, M. C., Aléssio, M. L., Léger, C. L., Bluet-Pajot, M. T., and Clauser, H. (1995). Effect of essential fatty acid deficiency on membrane fatty acid content and growth hormone stimulation of rat pituitaries during postnatal development. J. Lipid Res. 36, 1401-1406.

Thomas, B., and Beal, M. F. (2007). Parkinson's disease. Hum. Mol. Genet. 2, 183-194.

Tian, C., Fan, C., Liu, X., Xu, F., and Qi, K. (2011). Brain histological changes in young mice submitted to diets with different ratios of $n-6 / n-3$ polyunsaturated fatty acids during maternal pregnancy and lactation. Clin. Nutr. 30, 659-667.

Venkateshappa, C., Harish, G., Mythri, R. B., Mahadevan, A., Srinivas Bharath, M. M., and Shankar, S. K. (2012). Increased oxidative damage and decreased anti-oxidant function in aging human substantia nigra compared to striatum: implications for Parkinson's disease. Neurochem. Res. 37, 358-369.

Wang, X., and Michaelis, E. K. (2010). Selective neuronal vulnerability to oxidative stress in the brain. Front. Aging Neurosci. 2:12. doi: 10.3389/fnagi.2010.00012

Yang, L., Shah, K., Wang, H., Karamyan, V. T., and Abbruscato, T. J. (2011). Characterization of neuroprotective effects of biphalin, an opioid receptor agonist, in a model of focal brain ischemia. J. Pharmacol. Exp. Ther. 339, 499-508.
Yavin, E. (2006) Docosahexaenoic acid: a pluripotent molecule acting as a membrane fluidizer, a cellular anti-oxidant and a modulator of gene expression. Nutr. Health 18 , 261-262.

Zhang, W., Li, P., Hu, X., Zhang, F., Chen, J., and Gao, Y. (2011). Omega-3 polyunsaturated fatty acids in the brain: metabolism and neuroprotection. Front. Biosci. 17, 2653-2670.

Conflict of Interest Statement: The authors declare that the research was conducted in the absence of any commercial or financial relationships that could be construed as a potential conflict of interest.

Received: 09 March 2012; paper pending published: 17 April 2012; accepted: 10 August 2012; published online: 30 August 2012

Citation: Cardoso HD, Passos PP, Lagranha CJ, Ferraz AC, Santos
Junior EF, Oliveira RS, Oliveira PEL, Santos RCF, Santana DF, Borba JMC, Rocha-de-Melo A, Guedes RCA, Navarro DMAF, Santos GKN, Borner R, PicançoDiniz CW, Beltrão EI, Silva JF, Rodrigues MCA and Andrade da Costa BL (2012) Differential vulnerability of substantia nigra and corpus striatum to oxidative insult induced by reduced dietary levels of essential fatty acids. Front. Hum. Neurosci. 6:249. doi: 10.3389/fnhum. 2012.00249

Copyright (c) 2012 Cardoso, Passos, Lagranha, Ferraz, Santos Junior, Oliveira, Oliveira, Santos, Santana, Borba, Rocha-de-Melo, Guedes, Navarro, Santos, Borner, PicançoDiniz, Beltrão, Silva, Rodrigues and Andrade da Costa. This is an open-access article distributed under the terms of the Creative Commons Attribution License, which permits use, distribution and reproduction in other forums, provided the original authors and source are credited and subject to any copyright notices concerning any third-party graphics etc. 